\title{
Lamine kaplama kereste (LVL) rutubetinin basınç direnci üzerine etkisinin yapay zekâ ile belirlenmesi
}

\author{
Eser Sözen ${ }^{a, *}$ (D), Timuçin Bardak ${ }^{b}$ (D), Kadir Kayahan ${ }^{b}$ (id
}

\begin{abstract}
Özet: Yapı sektöründe kullanılan ahşap malzemeler, kullanım yerine bağlı olarak farklı yükleme çeşitlerine ve farklı dirençlere maruz kalmaktadır. Yükleme türüne uygun materyal kullanımı güvenlik, performans ve maliyet gibi önemli faktörleri etkilemektedir. Yapı sektöründe kullanılan ahşap materyallerde diğer bir önemli husus, odun-su ilişkileridir. Rutubet, odunun fiziksel, mekanik ve teknolojik (sertlik, aşınma) özellikleri üzerinde önemli değişikliklere neden olmaktadır. Bu çalışmada, soyma işlemi ile elde edilen $2 \mathrm{~mm}$ kayın (Fagus orientalis L.) kaplamlardan 5 katmanlı LVL (Laminated Veneer Lumber) üretimi gerçekleștirilmiștir. Üretilen LVL'ler dört farklı nem $(\% 0, \% 12, \% 18$ ve \% 25) değerinde ve liflere dik ve parallel olmak üzere iki farklı yönde basınç direncine tabi tutulmuştur. Belirtilen rutubet değerlerinden elde edilen verilerden yararlanılarak yapay zeka ile diğer rutubet miktarlarındaki basınç direnci değerleri tahmin edilmiştir. Tahminlerde Yapay Sinir Ağları (YSA), Karar Ağaçları (KA) ve Rastgele Orman (RO) algoritmaları kullanılmıştır. Mekanik test sonuçlarına göre, en yüksek basınç direnci değeri rutubeti $\% 0$ (firın kurusu) olan örneklerin liflere parallel yönde yapılan yüklemelerinde $\left(51,96 \mathrm{~N} / \mathrm{mm}^{2}\right)$ elde edilmiştir. En düşük basınç direnci değeri $\left(13,57 \mathrm{~N} / \mathrm{mm}^{2}\right)$ ise $\% 25$ rutubetli örneklerin liflere dik yönde yapılan yüklemelerinde saptanmıştır. En yüksek tahmin başarısı $R^{2}=0,984$ değeri ile Rastgele Orman algoritmasından elde edilmiştir. Sonuç olarak, farklı rutubetlerde LVL'lerin basınç direncini tahmin etmek için yapay zeka tekniklerinin çözüm olarak başarılı bir şekilde kullanılabileceği belirlenmiştir.

Anahtar kelimeler: LVL, Basınç direnci, Rutubet, Yapay zekâ, Karar ağaçları, Rastgele orman
\end{abstract}

\section{Determination of the effect of laminated veneer lumber (LVL) moisture content on pressure resistance by artificial intelligence}

\begin{abstract}
Wooden materials used in the building sector are exposed to different loading types and different strength depending on the place of use. The use of materials suitable for the type of loading affects important factors such as safety, performance and cost. Another important issue in wooden materials used in the building sector is wood-water relations. Moisture causes significant changes on the physical, mechanical and technological (hardness, wear) properties of wood. In this study, 5-layer LVL (Laminated Veneer Lumber) was produced from $2 \mathrm{~mm}$ beech (Fagus orientalis L.) veneer obtained by peeling process. Produced LVLs were subjected to four different moisture $(0 \%, 12 \%, 18 \%$ and $25 \%)$ compressio strength in two different directions, perpendicular and parallel to the fibers. Using the data obtained from the specified moisture values, the pressure resistance values in other moisture amounts were estimated by artificial intelligence. Artificial Neural Networks (ANN), Decision Trees (DT) and Random Forest (RF) algorithms are used in the predictions. According to the mechanical test results, the highest compression strength value (51.96 $\mathrm{N} / \mathrm{mm}^{2}$ ) was obtained in the loading parallel to the fibers of the samples with $0 \%$ moisture (oven dry). The lowest compression strength value $\left(13.57 \mathrm{~N} / \mathrm{mm}^{2}\right)$ was determined in the loading vertical direction to the fibers of $25 \%$ moisture samples. The highest prediction success was obtained from the Random Forest algorithm with a value of $R^{2}=0.984$. As a result, it has been determined that artificial intelligence techniques can be used successfully as a solution to predict the pressure resistance of LVLs at different humidity.
\end{abstract}

Keywords: LVL, Compression strength, Moisture, Artificial intelligence, Decision trees, Random forest

\section{Giriş}

Ahşap kaplamalardan elde edilen kontrplak ya da LVL gibi yapısal ürünler, ahşap yapı sektöründe yaygın olarak kullanılmaktadır. Biçilmiş keresteye göre geniş yüzeyler elde edilebilmesi, daha güvenilir mekanik özelliklere sahip olması ve daha uzun mesnet genişliklerinin geçilmesi bu ürünlerin önemli avantajlarındandır (Stark vd., 2010). Dünya çapında inşa edilen çok katlı ahşap binaların sayısının artmasıyla, bu ürünlerin kullanımlarının daha da artması beklenmektedir.
Farklı ağaç türlerinden yeni yapısal ürünlerin üretilmesi ve piyasaya sunulması için direnç özelliklerinin belirlenmesi, güvenli mühendislik tasarımlarına katkı sağlayacaktır (Gilbert vd., 2017).

LVL'nin dış mekan uygulamalarında kullanımı, boyutsal kararlılık ve biyolojik bozulma gibi çessitli dayanıklılık sorunları ile sınırlıdır. Dış ortamda kullanılan LVL levhaları çürümeye sebep olan yüksek nem ve sıcaklık değişimlerine maruz kalabilir. LVL'nin biyolojik dayanıklılığını artırmak için LVL'yi son işlemden geçirmek veya kaplamaların ticari

\footnotetext{
$\llbracket$ a Bartın Üniversitesi, Orman Fakültesi, Orman Endüstri Mühendisliği, Bartın, Türkiye

b Bartın Üniversitesi, Bartın Meslek Yüksekokulu, Mobilya ve Dekorasyon Programı, Bartın, Türkiye

@ * Corresponding author (İletişim yazarı): esozen@bartin.edu.tr

$\checkmark \quad$ Received (Geliş tarihi): 01.03.2021, Accepted (Kabul tarihi): 19.04.2021
}

Citation (Atıf): Sözen, E., Bardak, T., Kayahan, K., 2021. Lamine kaplama kereste (LVL) rutubetinin basınç direnci üzerine etkisinin yapay zekâ ile belirlenmesi. Turkish Journal of Forestry, 22(2): 157-164 DOI: $10.18182 /$ tjf.888829 
koruyucularla üretimden önce ön işlemden geçirilmesi önerilmektedir (Nzokou vd., 2005). Diğer taraftan uygulanan bu işlemlerin mekanik dirençleri düşürdügüne dair literatürde çok sayıda çalışma bulunmaktadır (Roos vd., 1993; Gomben ve Gorman 1994; De Groot vd., 1998; Aydemir vd., 2016). Ahşap kaplamalardan elde edilen yapısal ürünlerin termit, mantar ve dış ortam koşullarına karşı dayanımını arttırmak için diğer bir yaklaşım da doğal olarak bu etmenlere dayanıklı olan ağaç türlerinin kullanılmasıdır. Bazı odun türleri bulundurdukları ekstraktif maddelerden dolayı özellikle mantar ve termit gibi zararlılara karşı dayanıklılık gösterebilmektedir (Nzokou vd., 2005; Sivrikaya vd., 2015). Çolak vd., (2004) farklı tutkallar kullanarak elde ettiği LVL'leri iki farklı (\%45 ve \%65) bağıl nem ortamında bekletmiştir. Çalışma sonucunda sunulan verilere göre $\% 45$ bağıl nem ortamındaki örneklerin denge rutubet miktarı, $\% 65$ bağıl nem ortamında bekletilenlere göre daha düşüktür. Diğer taraftan aynı ortamda bekletilen örneklerde, kullanılan farklı tutkalların da denge rutubetinde farklılıklara neden olduğu görülmüştür.

Yapay zeka, bilgisayar bilimi içinde bulunan, makinelerin insanlardan bilişsel görevleri devralmasına izin vermeyi amaçlayan ve oldukça ilgi çeken bir alandır. Yapay zeka tabanlı teknikler, geleneksel modelleme tekniklerinin sınırlamalarını ortadan kaldırabilmektedir. Yapay zeka, farklı sistemlerde mükemmel doğruluk ile modelleme uygulamalarında umut vericidir (Khoshaim vd., 2021). Yapay zeka tekniklerinin geniş bir uygulama alanı vardır ve gerçek dünyada çok sayıda problem bu teknikler ile başarılı bir şekilde çözülmüştür. Orman endüstri alanında yapay zekaya dayalı çok sayıda bilimsel çalışma gerçekleştirilmiştir (Tiryaki vd., 2015; Bardak vd., 2016; Kurt vd. 2017; Kurt ve Karayilmazlar 2019; Ersen 2021). Buna karşın LVL'lerin üretimde verimliliği artırmak için yapay zekadan faydalanan çok sınırlı sayıda çalışma bulunmaktadır.

$\mathrm{Bu}$ çalışmada, kayın kaplamalardan elde edilen LVL'lerin liflere paralel ve liflere dik yöndeki basınç direnci dayanımı belirlenmiştir. Dört farklı rutubet oranında gerçekleştirilen bu statik testlerin yapay zeka ile işlenmiştir. Yapay zeka ile LVL'lerin \%0-\%25 rutubetleri arasındaki diğer rutubet değerlerindeki basınç değerleri tahmin edilmiştir. Güncel bilgi teknolojileri ile orman ürünlerinin etkileşimi açısından önemli olan bu çalışma, bu alanda gerçekleştirilecek yeni çalışmalara da kaynak sağlayacak niteliktedir.

\section{Materyal ve yöntem}

\subsection{Materyal}

LVL üretimi için kullanılan kaplamalar, Zonguldak'ın Devrek ilçesinde faaliyet gösteren bir firmadan temin edilmiştir. Kaplamalar, kayın (Fagus orientalis L.) tomruklarından soyma işlemi ile elde edilmiştir. $2 \mathrm{~mm}$ kalınlıkta soyulan kaplamalar $500 \times 500 \mathrm{~mm}$ ebatlarında ölçülendirilmiştir. Kaplama yüzeylerine herhangi bir temizlik (zımpara vb.) uygulanmamıştır. Firmadan temin edilen kaplamaların rutubeti $\% 8$ olarak ölçülmüştür. Bu kaplamalar, $\% 12$ 'lik denge rutubetine ulaşana kadar \%65 bağ 1 nem ve $20^{\circ} \mathrm{C}$ koşullarına ayarlanmış bir iklimlendirme dolabında tutulmuştur. Üzerinde budak, çatlak veya dalgalanma gibi kusur bulunan kaplamalar LVL üretiminde kullanılmamıştır. Yapıştırıcı olarak poliüretan (PU-D4) tutkalı kullanılmıştır.

\subsection{Yöntem}

\subsubsection{LVL Üretimi}

Çalışma kapsamında $2 \mathrm{~mm}$ kalınlıktaki kaplamalar kullanılarak beş katmanlı $12 \mathrm{~mm}$ kalınlıkta LVL üretimi gerçekleştirilmiştir. Tutkallama işlemi için dört kaplamanın üst yüzeyleri tutkallanmış ve üstüne beşinci bir kaplama yerleştirilmiştir (Şekil 1-a). Levha taslağı oluşturulurken LVL'nin karakteristik özelliği olan liflerinin yönlerinin birbirine paralel olmasına dikkat edilmiştir. Uygulanan tutkal miktarı yaklaşık $200 \mathrm{~g} / \mathrm{m}^{2}$ 'dir. 45 dakika pres süresi ve 1,2 $\mathrm{N} / \mathrm{mm}^{2}$ pres basıncı uygulanmıştır. Pres sonrası 500x500x12 $\mathrm{mm}$ ölçülerinde LVL levha elde edilmiştir. (Şekil 1-b). Numuneler, pres sonrası 24 saat oda sıcaklığında bekletildi. Daha sonra liflere paralel (Şekil 1-c) ve liflere dik (Şekil 1-d) basınç direnci için örnekler uygun ölçülerde kesilmiştir. Şekil 1 de LVL üretim aşamaları ve numunelerin hazırlanması gösterilmiştir.

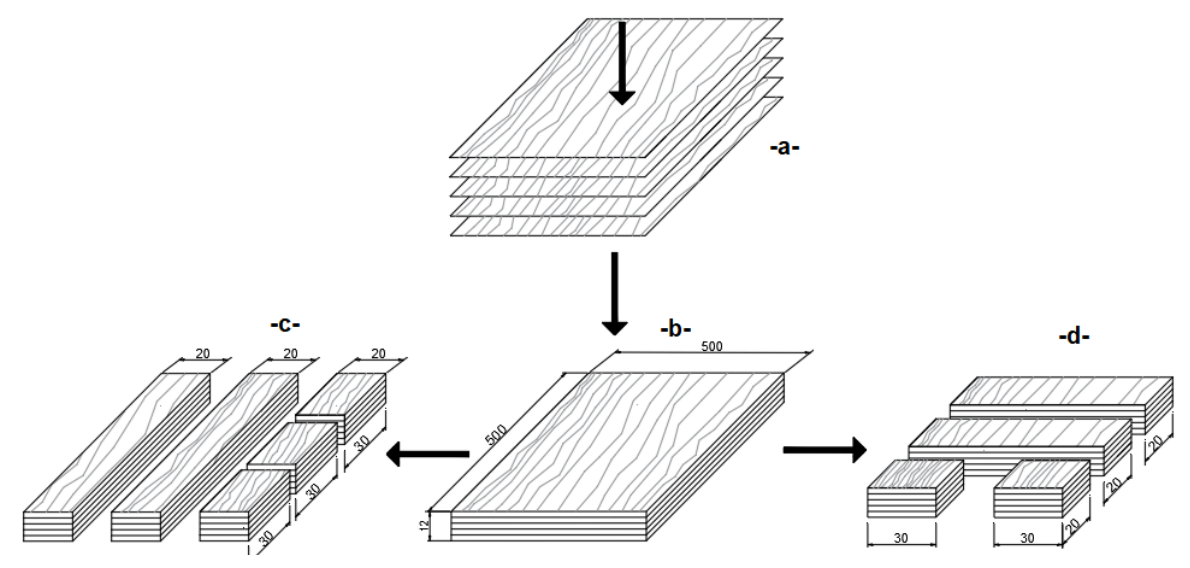

Şekil 1. LVL üretim aşamaları ve numunelerin hazırlanması (ölçüler mm). 
30x20x12 mm ölçülerinde hazırlanan numunelere $\% 0$ (firın kurusu) \%12, \%18 ve \%25 denge rutubetlerine ulaşmak için Çizelge 1'de verilen sıcaklık ve bağıl nem değerleri uygulanmıştır. Her varyasyon ayrı ayrı iklimlendirme kabinine koyulmuştur. Her varyasyon ile birlikte rutubetin kontrol edilmesi için test örnekleri ile aynı boyutta olan tam kuru örnekler de kabine yerleştirilmiştir. Hedeflenen ağırlığa ulaştıktan 24 saat sonra yapılan ağırlık ölçümlerinde değişim olmadığ tutulmuştur. LVL'lerin rutubet miktarlarının ve özgül ağırlıklarının belirlenmesinde sırasıyla TS 2471 (1976) ve TS 2472 (1976) standartlarına uyulmuştur. Örnek ağırlıklarının ölçülmesinde $\pm 0,01 \mathrm{~g}$ duyarlıklı hassas terazi, hacimlerin belirlenmesinde $\pm 0,01$ duyarlıklı dijital kumpas kullanılmıştır.

\subsubsection{Liflere paralel ve liflere dik basınç direnci testi}

Çalışma kapsamında dört farklı rutubetteki LVL örneklerinde liflere paralel ve liflere dik olmak üzere 2 farklı yönde basınç testleri uygulanmıştır. Her varyasyon için 10 örnek kullanılmış toplamda $80(4 \times 2 \times 10=80)$ adet örnek teste tabi tutulmuştur. Liflere paralel ve liflere dik basınç direnci testleri sirasıyla TS 2595 ve TS 2473 standartlarına göre gerçekleştirilmiştir. Şekil 2'de Liflere paralel (a) ve liflere dik (b) basınç direnci örnekleri gösterilmiştir.

Deneylerden önce, kuvvetin uygulandığı enine kesit alanı $\left(\mathrm{A}=20 \times 12=240 \mathrm{~mm}^{2}\right)$ hesaplanmıştır. Mekanik testte kırılma anındaki maksimum kuvvet $\left(\mathrm{F}_{\max }\right)$ belirlenmiş ve basınç dirençleri $\left(\sigma_{b}\right)(1)$ numaralı eşitlik kullanılarak belirlenmiştir.

$$
\sigma_{\mathrm{b}}=\frac{F_{\max }}{\mathrm{A}}\left(\mathrm{N} / \mathrm{mm}^{2}\right)
$$

Çizelge 1. İklim koşulları ve EMC değerleri (Bardak vd., 2018)

\begin{tabular}{cccc}
\hline $\begin{array}{c}\text { Sıcaklık } \\
\left({ }^{\circ} \mathrm{C}\right)\end{array}$ & $\begin{array}{c}\text { Bağıl nem } \\
(\%)\end{array}$ & $\begin{array}{c}\text { Süre } \\
(\text { gün })\end{array}$ & $\begin{array}{c}\text { Rutubet miktarı } \\
(\%)\end{array}$ \\
\hline $103 \pm 2$ & 0 (Fırında) & 3 & 0 (Fırın kurusu) \\
$20 \pm 2$ & 65 & 2 & 12 \\
$15 \pm 2$ & 80 & 4 & 18 \\
$10 \pm 2$ & 90 & 10 & 25 \\
\hline
\end{tabular}

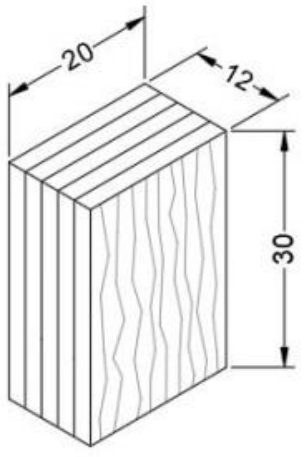

-a-

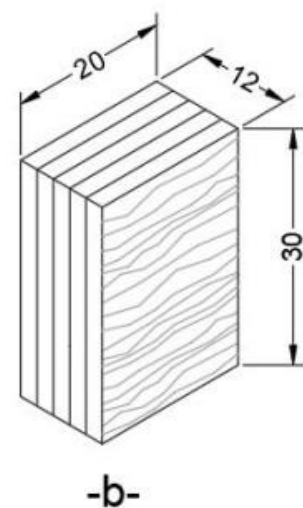

Şekil 2. Liflere paralel (a) ve liflere dik (b) basınç direnci örneklerinin ölçüleri (mm)
Testler, 10 tonluk üniversal test cihazında $2 \mathrm{~mm} /$ dakika yükleme hızıyla gerçekleştirilmiştir. Şekil 3-a 'da liflere paralel, 3-b'de liflere dik basınç testlerinin gerçekleştirildiği test düzeneklerine ait konfigürasyon gösterilmiştir.

\subsubsection{Verilerin değerlendirilmesi}

Mekanik testler sonucunda elde edilen verilerin istatistiksel analizinde SPSS 16.0 programı kullanılmıştır. Oluşturulan varyasyonlar arasında anlamlı farklılığın olup olmadığ1 tek yönlü varyans analizi (ANOVA) ile belirlenmiştir. Anlamlı farklılığın oluştuğu varyasyonlarda homojenlik gruplarının oluşturulmasında Duncan analizi kullanılmıştır.

\subsubsection{Yapay zekâ ile basınç dirençlerinin tahmini}

Çalışmada uygulanan metodoloji, veri toplama, veri hazırlama, model optimizasyonu, yük tahmini, test ve simülasyon aşamalarından oluşmaktadır. Birinci aşamada veriler deney yöntemi ile toplanmış ve elde edilen veriler modellere uygun şekilde hazırlanmıştır. Yapay Sinir Ağları (YSA), Karar Ağaçları (KA) ve Rastgele Orman (RO) algoritmaları tahmin için kullanılmıştır. İkinci aşamada modelin parametreleri otomatik olarak farklı kombinasyonlar karşılaştırılarak optimize edilmiştir. Şekil 4'te modellerin optimizasyonu için kullanılan proses, Çizelge 2'de optimizasyon sonucu belirlenen model parametreleri gösterilmiştir.

Diğer aşamada, veri iki kısma ayrılmıştır. Bunlar; modelin eğitiminde kullanılan \%70'lik kısım ve modelin testi için kullanılan \%30'luk kısımdır. Modellerde yükleme türü ve rutubet girdi, basınç direnci çıktı olarak kullanılmıştır. Aynı zamanda çalışmada veri madenciliği alanında yaygın olarak kullanılan Yapay Sinir Ağları (YSA), Karar Ağaçları (KA) ve Rastgele Orman (RO) algoritmalarının tahmin performansı karşılaştırılmıştır.
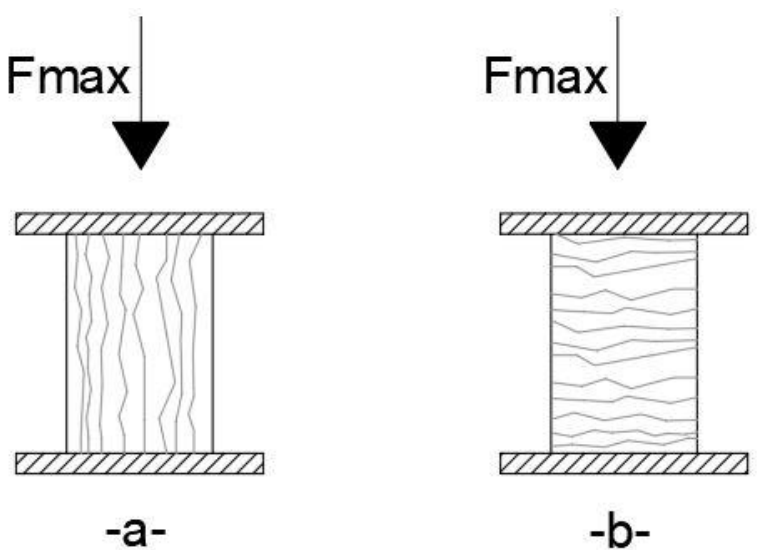

Şekil 3. Liflere paralel (a) ve dik (b) basınç direnci test düzeneği konfigürasyonu. 
Yapay sinir ağları, (YSA) biyolojik sinir ağlarından esinlenilmiş ve sinir ağlarının işleyişine benzer şekilde çalışan bir algoritmadır (Sözen vd., 2018). Karar Ağaçları (KA), hızlı eğitim süreleri ve iyi yorumlanabilmeleri nedeniyle tercih edilen makine öğrenimi modelleridir (Pereira vd., 2021). Rastgele Orman (RO) tahmin için kullanılan popüler bir veri madenciliği tekniğidir (BouHamad ve Jamali, 2020). Bu algoritma gözetimli öğrenme türünde karar ağaçları topluluğunu kullanan etkili bir algoritmadır (Gholizadeh vd., 2020). Çalışmada tahmin modellerini kurmak için RapidMiner yazılımından faydalanılmıştır. $\mathrm{Bu}$ yazılım operatörler ile prosesler oluşturularak kullanılmaktadır. Her operatörün bir görevi vardır örneğin; veriyi yüklemek, veriyi düzenlemek, model kurmak gibi. Modellerin performansı belirlemek için kullanılan proses Şekil 5'te gösterilmiştir.

Modellerin performansını belirlemek için belirlilik katsayısı $\left(\mathrm{R}^{2}\right)$, ortalama hata kare kökü (RMSE) ve ortalama karesel hata (MSE) sonuçları sırasıyla (2), (39 ve (4) numaralı eşitliklerden faydalanılarak hesaplanmıştır. Bu ölçütler veri madenciliği çalışmalarında modelleri değerlendirmek için tercih edilmektedir (Kim vd.,2019).

$$
\begin{aligned}
& \mathrm{R}^{2}=\left[\frac{\sum\left(Y_{p-} \overline{Y_{p}}\right)\left(Y_{o}-\overline{Y_{o}}\right)}{\sqrt{\sum\left(Y_{p-} \overline{Y_{p}}\right)^{2}\left(Y_{o}-\overline{Y_{o}}\right)^{2}}}\right]^{2} \\
& R M S E=\sqrt{\frac{1}{n} \sum_{i=0}^{n}\left(Y_{o}-Y_{p}\right)^{2}} \\
& \mathrm{MSE}=\mathrm{RMSE}^{2}
\end{aligned}
$$

YO ve YP sırasıyla ölçülen ve tahmin edilen değerlerdir

Son olarak her bir model ile simülasyonlar oluşturulmuştur. Buradaki amaç en yüksek eğilme direnci için optimum girdileri belirlemekti. Gerçek zamanlı simülasyonlar kullanılarak istenen herhangi bir basınç direnci için girdileri bulmak mümkündür. Şekil 6'da karar ağacı

\begin{tabular}{|c|c|c|c|c|c|}
\hline \multicolumn{2}{|c|}{ Yapay Sinir Ağları (YSA) } & \multicolumn{2}{|c|}{ Karar Ağaçları (KA) } & \multicolumn{2}{|c|}{ Rastgele Orman (RO) } \\
\hline Gizli katmanlar & 2 & Kriter & En küçük kare & Kriter & En küçük kare \\
\hline Eğitim döngüleri & 250 & Maksimum derinlik & 4 & Ağaç sayısı & 150 \\
\hline Öğrenme oran 1 & 0.01 & & & Maksimum derinlik & 4 \\
\hline
\end{tabular}
algoritması ile kurulan bir simülasyon gösterilmiştir.

Çizelge 2. Optimizasyon sonucu belirlenen model parametreleri

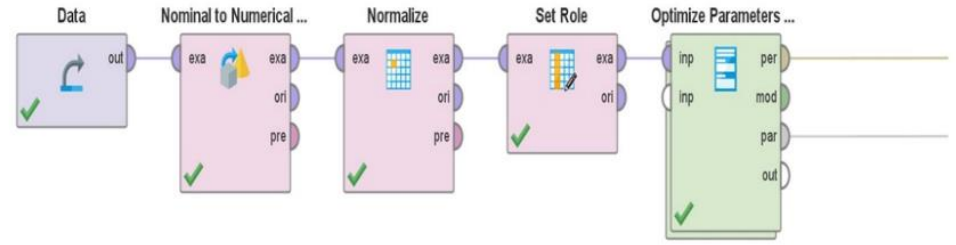

Şekil 4. Modellerin optimizasyonu için kullanılan proses

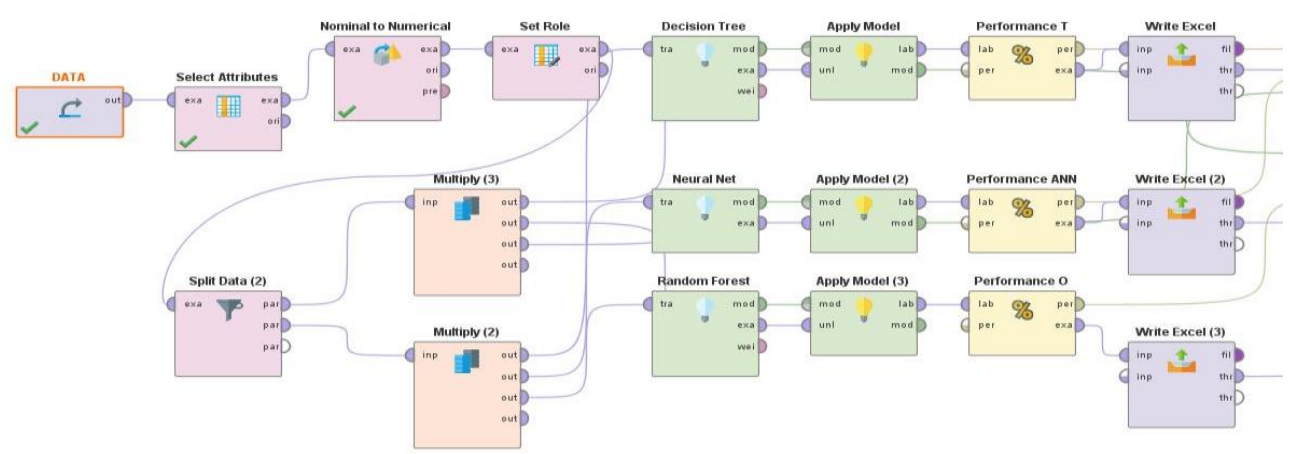

Şekil 5. Modellerin performansı belirlemek için kullanılan proses

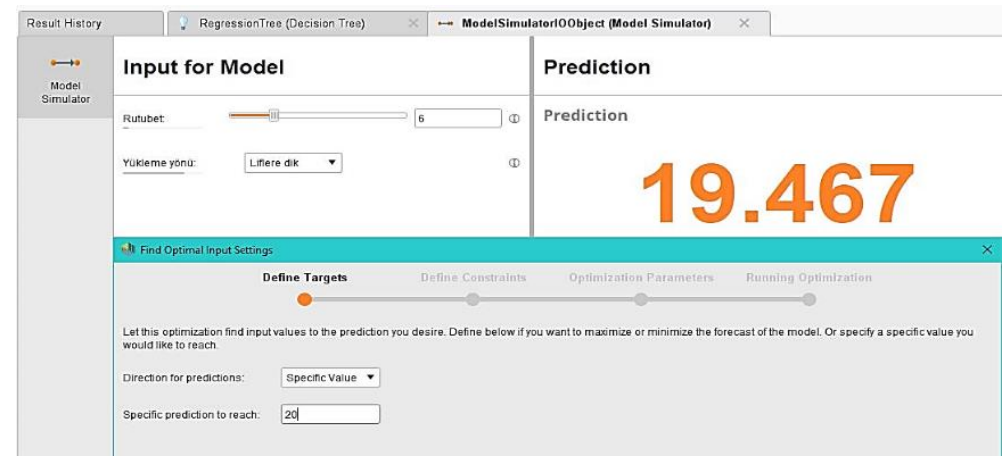

Şekil 6. Karar ağacı algoritması ile kurulan bir simülasyon 


\section{Bulgular ve tartışma}

\subsection{Basınç testi sonuçları}

Farklı rutubetlerde liflere paralel ve liflere dik yönde gerçekleştirilen basınç testi sonuçları Çizelge 3'te sunulmuştur. Testler sırasında maksimum kırılma kuvvetleri $\left(F_{\max }\right)$ kaydedilmiş ve standart sapma değerleri hesaplanmıştır. Kuvvetin uygulandığı alan ve $F_{\max }$ değeri ile eşitlik (1)'de verilen formülden yararlanılarak basınç direnci değerleri hesaplanmıştır. Deformasyon verileri otomatik olarak üniversal test makinesinden alınmıştır. Üretilen LVL'lerin hava kurusu (\%12) yoğunlukları ortalama 0,69 $\mathrm{gr} / \mathrm{cm}^{3}$ olarak belirlenmiştir. Uygulanan rutubet miktarları doğal olarak yoğunlukta değişimlere neden olmuştur. \%18 ve $\% 25$ rutubetli örneklerde yoğunluklarda artışlar, firın kurusu (\%0) örneklerde azalmalar gerçekleşmiştir. Çizelge 3'te görülen tüm veriler testi gerçekleştirilen 10 örneğin ortalamasidır.

Gerçekleştirilen basınç testlerinde en yüksek basınç dayanım değerini $51,96 \mathrm{~N} / \mathrm{mm}^{2}$ ile firın kurusu $(\% 0)$ örnekler, liflere paralel yükleme yönünde vermiştir. \%12 rutubetli örneklerin liflere paralel basınç dirençleri de 50,71 $\mathrm{N} / \mathrm{mm}^{2}$ ile ikinci en yükssek basınç dayanımı sağlamıştır. \%18 ve $\% 25$ rutubetli örneklerin liflere paralel dayanım değerleri sirasiyla $40,50 \mathrm{~N} / \mathrm{mm}^{2}$ ve $31,45 \mathrm{~N} / \mathrm{mm}^{2}$ olarak tespit edilmiştir. $\mathrm{Bu}$ değerler liflere paralel en yüksek basinç değerini oluşturan firın kurusu örneklere göre sırasıyla \%22 ve $\% 39$ oranında daha düşük değerlerdir.

Çalışma sonuçları literatür ile karşılaştırıldığında elde edilen sonuçların daha önce yapılan benzer çalışmalar ile benzerlik gösterdiği görülmektedir. Aydın vd., (2004) okaliptus (Eucalyptus camaldulensis Dehn.) ve kayin (Fagus orientalis L.) kaplamalarından PVA ve üre formaldehit kullanarak elde ettiği LVL'lerin fiziksel ve mekanik özelliklerini incelediği çalışmalarında liflere paralel basınç direnci değerlerini belirlemişlerdir. Üre formaldehit kullanılan okaliptus ve kayın LVL'lerin liflere paralel basınç direnci değerlerini sırasıyla $51,7 \mathrm{~N} / \mathrm{mm}^{2}$ ve $55,3 \mathrm{~N} / \mathrm{mm}^{2}$ olarak verilmiştir. Okaliptus odununun özgül ağırlığının kayına göre daha düşük olmasına rağmen daha yüksek liflere paralel basınç direnci değerleri göstermesinde, okaliptüs kaplamalarının daha pürüzsüz bir yüzeye sahip olmasına, dolayısıyla daha fazla tutkal emme potansiyelinin etkili olduğunu vurgulamışlardır. Yine başka bir çalıșmada (Kurt vd., 2012) hızlı gelişen bir tür olan İzmit kavak klonundan (Populus deltoides) soyma kaplamalarla elde ettiği LVL'lerde fenol formaldehit tutkalına farklı dolgu maddeleri ekleyerek performanslarını değerlendirmişlerdir. Çalışma sonucunda kontrol örneklerinde liflere paralel basınç direnci değerini $55,59 \mathrm{~N} / \mathrm{mm}^{2}$ olarak belirlemişlerdir. de Souza vd., (2011) Pinus oocarpa ve Pinus kesiya kaplamalarından elde ettikleri LVL'lerin liflere paralel basınç direnci değerlerini sırasıyla $55 \mathrm{~N} / \mathrm{mm}^{2}$ ve $57 \mathrm{~N} / \mathrm{mm}^{2}$ olarak tespit etmişlerdir. Yapraklı ağaçlara göre daha yüksek çıkan bu değerlerin, iğne yapraklı ağaçlardaki traheidlerin uzunluklarından kaynakladığını bildirmişlerdir.

Fırın kurusu ve \%12 rutubetli örneklerin en yüksek liflere paralel basınç direnci değerlerini verdiği görülmektedir. Bu durum ağaç malzemenin kurutulmasının ve denge rutubeti olarak ifade edilen ve yaklaşık \%10-\%12 olarak belirtilen rutubet değerinin önemini ortaya koymaktadır. Rutubet miktarı arttıkça basınç direnci değerlerinde düşüş görülmüştür. Yapılan bir çalışmada (Örs ve Keskin, 2008) artan rutubet miktarının genel olarak odunun mekanik özelliklerini düşürdüğünü, ancak şok direncinin bu genelleme dışında olduğu bildirilmiştir.

Liflere dik basınç direnci değerlerinde \%12 rutubetli örnekler ortalama $23,67 \mathrm{~N} / \mathrm{mm}^{2}$ ile en yüksek değeri vermiştir. Daha sonra sırasıyla \%0 (fırın kurusu), \%18 ve \%25 rutubetli örnekler sıralanmıştır. Liflere dik basınç direnci değerlerinin aynı rutubet değerlerindeki liflere paralel basınç direnci değerleri arasındaki farkları yüzdesel olarak Çizelge 4'te ifade edilmiştir.

Çizelge 4'te görüldüğ̈̈ gibi, liflere dik basınç direnci değerleri, bütün varyasyonlarda \%50'den fazla (ortalama \%59,5) düşüş göstermiştir. Çalışma kapsamında elde edilen bilgiler ışığında kullanım yerinde basınç direncine maruz kalacak LVL'lerin, liflere paralel yönde bu kuvvetlere karş1 koyacak şekilde tasarlanması daha uygun olacaktır. Odunda fiziksel ve mekanik özelliklerin incelendiği çalışmalara bakıldığında basınç dirençlerinde sadece liflere paralel yöndeki testlerin gerçekleştirildiği görülmüştür (Aydın vd., 2004; Pambou Nziengui vd., 2018; Wang vd., 2014; Jiang vd., 2012). Gerçekleştirilen çalışma ile bu alandaki bir eksikliğin giderilmesine katkı sağlanmıştır. Testler sırasında kaydedilen deformasyon miktarları incelendiğinde liflere dik basınç direncine tabi tutulan örnekler daha yüksek deformasyon miktarı göstermiştir. Bu durumun oluşmasında odunu oluşturan hücrelerin (yapraklı ağaçlarda trahelerin) yönleri etkili olmaktadır. Aynı deformasyon miktarları rutubet miktarları açısından değerlendirildiğinde, doğrusal veya ters orantı olmadığ 1 görülmüştür. Bunun nedenlerinin ise tutkal, tutkal hattı, tutkalın rutubet veya sicaklıktan etkilenmesi gibi farklı etkileşimler olabileceği düşünülmektedir.

Çizelge 4. Rutubet miktarına göre liflere paralel ve liflere dik basınç direnci değerleri arasındaki farklar

\begin{tabular}{lccl}
\hline $\begin{array}{l}\text { Rutubet } \\
\text { değerleri }\end{array}$ & $\begin{array}{c}\text { Liflere paralel basınç } \\
\text { direnci }\left(\mathrm{N} / \mathrm{mm}^{2}\right)\end{array}$ & $\begin{array}{c}\text { Liflere dik basınç } \\
\text { direnci }\left(\mathrm{N} / \mathrm{mm}^{2}\right)\end{array}$ & $\begin{array}{l}\text { Fark } \\
(\%)\end{array}$ \\
\hline$\% 0$ & 51,96 & 19,49 & $-62,5$ \\
$\% 12$ & 50,71 & 23,67 & $-53,3$ \\
$\% 18$ & 40,50 & 13,96 & $-65,5$ \\
$\% 25$ & 31,45 & 13,57 & $-56,9$ \\
\hline
\end{tabular}

Çizelge 3. Çalışmada gerçekleştirilen basınç testi sonuçları

\begin{tabular}{|c|c|c|c|c|c|}
\hline Rutubet içeriği (\%) & Test yükleme yönü & $\mathrm{F}_{\max }(\mathrm{N})$ & Standart sapma & Basınç direnci $\left(\mathrm{N} / \mathrm{mm}^{2}\right)$ & Deformasyon (mm) \\
\hline \multirow{2}{*}{$\% 0$ (Firın kurusu) } & Liflere dik & 4678 & \pm 425 & 19,49 & 3,59 \\
\hline & Liflere paralel & 12470 & \pm 1034 & 51,96 & 1,75 \\
\hline \multirow{2}{*}{$\% 12$} & Liflere dik & 5681 & \pm 288 & 23,67 & 6,04 \\
\hline & Liflere paralel & 12170 & \pm 1267 & 50,71 & 2,44 \\
\hline \multirow{2}{*}{$\% 18$} & Liflere dik & 3350 & \pm 323 & 13,96 & 4,62 \\
\hline & Liflere paralel & 9720 & \pm 583 & 40,50 & 1,34 \\
\hline \multirow{2}{*}{$\% 25$} & Liflere dik & 3257 & \pm 251 & 13,57 & 5,8 \\
\hline & Liflere paralel & 7548 & \pm 397 & 31,45 & 1,44 \\
\hline
\end{tabular}


Liflere dik ve liflere paralel basınç direnci sonuçlarının kendi aralarında anlamlı bir fark oluşturduğu tek yönlü varyans analizi (Analysis of variance-ANOVA) ile belirlenmiştir. Liflere dik basınç direnci değerlerinde gruplar arasında anlamlı bir fark olduğu $(\mathrm{F}=62,898 ; \mathrm{p}=0,000<0,05)$ tespit edilmiş ve gruplar arasındaki farklılıklar Duncan testi ile sunulmuştur. Çizelge 5'te liflere dik basınç direnci Duncan testi sonuçları gösterilmiştir.

Duncan testi sonuçlarına göre liflere dik basınç direnci değerlerinde 3 farklı grup oluşmuştur. \%12 rutubet miktarı en yüksek grubu, firın kurusu örnekler $(\% 0)$ ikinci grubu ve son olarak \%18 ve \%25 rutubetli örnekler üçüncü grubu oluşturmuştur. Bu sonuçlar ışığında liflere dik yönde basınç direncine maruz kalacak kayın LVL'lerin rutubetinin \%18 veya \%25 olmasının direnç değerlerini etkilemediği söylenebilir. Diğer taraftan $\% 0$ ve $\% 12$ rutubetlerde anlaml farklılıkların oluştuğu bu farkın önemli olduğu (farklı gruplar oluşturduğu) görülmüştür.

Liflere paralel basınç direnci değerleri arasında anlamlı farklılığın oluştuğu $(\mathrm{F}=136,070 ; \mathrm{p}=0,000<0,05)$ varyans analizi ile belirlenmiştir. Varyasyonların oluşturduğu gruplar Duncan testi ile belirlenmiş ve Çizelge 6'da gösterilmiştir.

Çizelge 6'te görüldüğü gibi en yüksek grubu $\% 12$ ve $\% 0$ rutubetli örnekler oluştururken, en düşük grupta $\% 25$ rutubetli örnekler yer almıştır. Liflere dik basınç direncinde farklı gruplarda olan $\% 12$ ve $\% 25$ rutubetli örnekler liflere paralel basınç direncinde aynı grupta yer almıştır. Buna göre liflere dik basınç direncine maruz kalacak yüklemelerde LVL kullanımında \%12 veya daha düşük rutubetlerin direnç üzerinde etkili olduğu söylenebilir.

\subsection{Yapay zekâ ile basınç direnci tahminleri}

Çizelge 7'de algoritmaların test kısmı için ölçülen gerçek değerler, tahmin edilen değerler ve yüzde hataları gösterilmiştir. Bu sonuçlara göre Yapay Sinir Ağları (YSA), Karar Ağaçları (KA) ve Rastgele Orman (RO) algoritmalarının tahmin performansları ise Çizelge 8 'de gösterilmiştir.

Çizelge 8'deki sonuçlar değerlendirildiğinde, test kısmı için en yüksek başarı Rastgele Orman $\left(R^{2}=0.984\right)$ algoritmasında, en düşük başarı Yapay Sinir Ağları $\left(R^{2}=\right.$ 0.978 ) algoritmasında görülmektedir. Literatürde $\mathrm{R}^{2}$ değerini 0,7'den büyük olması durumunda modelin tatminkâr olduğu belirtilmiştir (Wadie vd., 2006). Bu sonuçlara göre her üç model ile kurulan simülasyonlar güvenilirdir. Çizelge 9'da maksimum basınç direnci için modellerin belirlediği girdiler gösterilmiştir.

Çizelge 5. Liflere dik basınç direnci Duncan testi sonuçları

\begin{tabular}{cccc}
\hline \multirow{2}{*}{ Rutubet oranı } & \multicolumn{3}{c}{ Gruplar } \\
\cline { 2 - 4 } & $\mathrm{A}$ & $\mathrm{B}$ & $\mathrm{C}$ \\
\hline$\% 25$ & 13,57 & & \\
$\% 18$ & 13,96 & & \\
$\% 0$ & & 19,49 & \\
$\% 12$ & & & 23,67 \\
\hline
\end{tabular}

Çizelge 6. Liflere paralel basınç direnci Duncan testi sonuçları

\begin{tabular}{cccc}
\hline \multirow{2}{*}{ Rutubet oranı } & \multicolumn{3}{c}{ Gruplar } \\
\cline { 2 - 4 } & $\mathrm{A}$ & $\mathrm{B}$ & $\mathrm{C}$ \\
\hline$\% 25$ & 31,45 & & \\
$\% 18$ & & 40,50 & \\
$\% 12$ & & & 50,71 \\
$\% 0$ & & & 51,96 \\
\hline
\end{tabular}

Çizelge 7. Test kısmı için ölçülen gerçek değerler, tahmin edilen değerler ve yüzde hataları

\begin{tabular}{|c|c|c|c|c|c|c|c|}
\hline Deney No & Gerçek Değer & Tahmin YSA & Hata (\%) YSA & Tahmin KA & Hata (\%) KA & Tahmin RO & Hata (\%) RO \\
\hline 1 & 15,05 & 20,79 & 38,09 & 20,37 & 35,30 & 20,25 & 34,54 \\
\hline 2 & 17,50 & 20,79 & 18,79 & 20,37 & 16,39 & 20,25 & 15,74 \\
\hline 3 & 19,79 & 20,79 & 5,03 & 20,37 & 2,91 & 20,25 & 2,34 \\
\hline 4 & 50,84 & 52,96 & 4,17 & 52,49 & 3,23 & 52,23 & 2,73 \\
\hline 5 & 49,87 & 52,96 & 6,20 & 52,49 & 5,25 & 52,23 & 4,74 \\
\hline 6 & 51,46 & 52,96 & 2,92 & 52,49 & 2,00 & 52,23 & 1,51 \\
\hline 7 & 22,48 & 23,02 & 2,39 & 23,82 & 5,98 & 23,84 & 6,05 \\
\hline 8 & 23,67 & 23,02 & 2,75 & 23,82 & 0,66 & 23,84 & 0,73 \\
\hline 9 & 54,96 & 49,75 & 9,49 & 50,05 & 8,94 & 50,18 & 8,70 \\
\hline 10 & 53,02 & 49,75 & 6,17 & 50,05 & 5,60 & 50,18 & 5,35 \\
\hline 11 & 48,79 & 49,75 & 1,97 & 50,05 & 2,59 & 50,18 & 2,86 \\
\hline 12 & 14,22 & 18,12 & 27,48 & 14,17 & 0,30 & 14,21 & 0,05 \\
\hline 13 & 12,25 & 18,12 & 48,00 & 14,17 & 15,75 & 14,21 & 16,04 \\
\hline 14 & 13,94 & 18,12 & 30,03 & 14,17 & 1,70 & 14,21 & 1,96 \\
\hline 15 & 39,14 & 41,77 & 6,74 & 40,25 & 2,85 & 40,35 & 3,10 \\
\hline 16 & 41,96 & 41,77 & 0,46 & 40,25 & 4,08 & 40,35 & 3,84 \\
\hline 17 & 41,72 & 41,77 & 0,12 & 40,25 & 3,52 & 40,35 & 3,29 \\
\hline 18 & 40,64 & 41,77 & 2,77 & 40,25 & 0,96 & 40,35 & 0,72 \\
\hline 19 & 13,15 & 14,30 & 8,73 & 13,62 & 3,59 & 13,54 & 2,94 \\
\hline 20 & 14,91 & 14,30 & 4,09 & 13,62 & 8,62 & 13,54 & 9,20 \\
\hline 21 & 12,27 & 14,30 & 16,52 & 13,62 & 11,02 & 13,54 & 10,32 \\
\hline 22 & 32,46 & 32,60 & 0,45 & 31,11 & 4,16 & 31,02 & 4,42 \\
\hline 23 & 31,58 & 32,60 & 3,24 & 31,11 & 1,50 & 31,02 & 1,77 \\
\hline 24 & 32,68 & 32,60 & 0,23 & 31,11 & 4,81 & 31,02 & 5,06 \\
\hline
\end{tabular}

YSA: Yapay Sinir Ağları, KA: Karar Ağac1, RO: Rastgele Orman 
Çizelge 8. Çalışmada kullanılan algoritmaların performanslarının karşılaştırılması

\begin{tabular}{lcccccc}
\hline \multirow{2}{*}{ Model } & \multicolumn{3}{c}{ Test kısmı } & \multicolumn{3}{c}{ Eğitim k1smı } \\
\cline { 2 - 7 } & $\mathrm{R}^{2}$ & RMSE & MSE & $\mathrm{R}^{2}$ & RMSE & MSE \\
\hline YSA & 0.978 & 2.762 & 7,629 & 0,953 & 4,457 & 19,865 \\
KA & 0.983 & 2.064 & 4,260 & 0,978 & 2,175 & 4,731 \\
RO & 0.984 & 2.004 & 4,016 & 0,978 & 2,175 & 4,731 \\
\hline
\end{tabular}

YSA: Yapay Sinir Ağları, KA: Karar Ağac1, RO: Rastgele Orman

Çizelge 9. Maksimum basınç direnci için modellerin belirlediği girdiler

\begin{tabular}{lccc}
\hline & YSA & KA & RO \\
\hline Basınç Direnci $\left(\mathrm{N} / \mathrm{mm}^{2}\right)$ & 57,151 & 52,485 & 52,485 \\
Rutubet oranı $(\%)$ & 4 & 6 & 6 \\
Test yükleme yönü & Liflere paralel & Liflere paralel & Liflere paralel \\
\hline YSA: Yapay Sinir Ağları, KA: Karar Ağacı, RO: Rastgele Orman
\end{tabular}

Çizelge 9'daki veriler incelendiğinde, tüm modeller (YSA, KA ve RO) en yüksek basınç direnci için birbirine yakın değerler vermiştir. Karar ağacı ve rastgele orman algoritmaları tahminlerine göre en yüksek basınç direncine ulaşmak LVL'lerin \%6 rutubetin uygun olacağı görülmüştür. Yapay sinir ağlarında ise bu rutubet değeri $\% 4$ olarak tahmin edilmiştir. Ahşap malzemenin kullanım yerindeki rutubet değerlerine göre mekanik performanslarının değişeceği göz önüne alındığında bu tahminlerin önemi daha da artmaktadır.

\section{Sonuc ve öneriler}

Bu çalışmada, LVL üretiminde rutubet ve yükleme yönün etkisini belirlemek için yapay zekâ modelleri uygulanmıştır. Mekanik testler sonucunda, liflere paralel basınç direnci performanslarının, liflere dik basınç direnci değerlerinden \%147 daha yüksek olduğu tespit edilmiştir. Bu nedenle basınç direncine maruz kalacak yüklemelerde ağaç malzemelerin liflere dik yönde kullanılması performansına katkı sağlayacaktır. \%18 ve \%25 rutubetli örneklerin liflere paralel basınç direnci değerlerinde anlamlı düşüşler görülmüştür. Bunun sonucu olarak ağaç malzemelerin rutubetinin düşük oranlarda $(\% 5-\% 7)$ olması, kurutma maliyetleri düşünüldüğünde en azından $\% 12$ rutubetlerde olması tavsiye edilebilir. Yapay Sinir Ağları (YSA), Karar Ağaçları (KA) ve Rastgele Orman (RO) algoritmaları kullanılarak tahmin modelleri yüksek doğruluk oranında tahminlerde bulunmuştur. Rastgele orman algoritması ile kurulan model en yüksek tahmin başarısını göstermiştir. Sonuç olarak, yapay zekâ tahmin performansları üretim proseslerindeki verilerle, farklı şartlarda üretilen ürünlerin performansına ulaşma potansiyeli vardır. Değişken sayılarının bilinmesi ve doğruluğunun yanında seçilen algoritmaların da uygunluğu sonuç üzerinde etkili olmaktadır.

\section{Kaynaklar}

Aydemir, D., Civi, B., Alsan, M., Can, A., Sivrikaya, H., Gunduz, G., Wang, A., 2016. Mechanical, morphological and thermal properties of nano-boron nitride treated wood materials. Maderas Ciencia y Tecnología, 18(1): 19-32.

Aydın, İ., Çolak, S., Çolakoğlu, G., Salih, E., 2004. A comparative study on some physical and mechanical properties of Laminated Veneer Lumber (LVL) produced from Beech (Fagus orientalis Lipsky) and Eucalyptus (Eucalyptus camaldulensis Dehn.) veneers. Holz als Roh-und Werkstoff, 62(3): 218-220.
Bardak, S., Tiryaki, S., Bardak, T., Aydin, A., 2016. Predictive performance of artificial neural network and multiple linear regression models in predicting adhesive bonding strength of wood. Strength of Materials, 48(6): 811-824.

Bardak, T., Sozen, E., Kayahan, K., Bardak, S. 2018. The impact of nanoparticles and moisture content on bonding strength of urea formaldehyde resin adhesive. Drvna Industrija, 69(3): 247-252.

Bou-Hamad, I., Jamali, I., 2020. Forecasting financial time-series using data mining models: A simulation study. Research in International Business and Finance, 51: 101072.

Çolak, S., Aydin, I., Demirkir, C., Çolakoğlu, G., 2004. Some technological properties of laminated veneer lumber manufactured from pine (Pinus sylvestris L.) veneers with melamine added-UF resins. Turkish Journal of Agriculture and Forestry, 28(2): 109-113.

De Groot, R.C., Gjovik, L.R., Crawford, D., Woodward, B., 1998. Field durability of CCA-and ACA-treated plywood composed of hardwood and softwood veneers. Forest Products Journal, 48: 76-82.

de Souza, F., Del Menezzi, C.H.S., Júnior, G.B., 2011. Material properties and nondestructive evaluation of laminated veneer lumber (LVL) made from Pinus oocarpa and P. kesiya. European Journal of Wood and Wood Products, 69(2): 183-192.

Ersen, N., 2021. Analysis of furniture products' contribution to Turkey's economy with a hybrid multi-criteria decision making method. BioResources, 16(1): 339-353.

Gholizadeh, M., Jamei, M., Ahmadianfar, I., Pourrajab, R., 2020. Prediction of nanofluids viscosity using random forest (RF) approach. Chemometrics and Intelligent Laboratory Systems, 201: 104010.

Gilbert, B.P., Bailleres, H., Zhang, H., McGavin, R.L., 2017. Strength modelling of laminated veneer lumber (LVL) beams. Construction and Building Materials, 149: 763-777.

Gomben, P.C., Gorman, T.M., 1994. Treatability of lodgepole pine laminated veneer lumber. Forest Products Journal, 44(2): 39.

Jiang, Z., Wang, H., Tian, G., Yu, Y., 2012. Sensitivity of several selected mechanical properties of moso bamboo to moisture content change under the fibre saturation point. BioResources, 7(4): 5048-5058.

Khoshaim, A.B., Elsheikh, A.H., Moustafa, E.B., Basha, M., Mosleh, A.O., 2021. Prediction of residual stresses in turning of pure iron using artificial intelligence-based methods. Journal of Materials Research and Technology, 11: 2181-2194

Kim, S., Pan, S., Mase, H., 2019. Artificial neural network-based storm surge forecast model: Practical application to Sakai Minato, Japan. Applied Ocean Research, 91: 101871.

Kurt, R., Meriç, H., Aslan, K., Çil, M., 2012. Laminated veneer lumber (LVL) manufacturing using three hybrid poplar clones. Turkish Journal of Agriculture and Forestry, 36(2): 237-245.

Kurt, R., Karayilmazlar, S., Imren, E., Çabuk, Y. 2017. Yapay sinir ağları ile öngörü modellemesi: Türkiye kağıt-karton sanayi örneği. Bartın Orman Fakültesi Dergisi, 19(2): 99-106.

Kurt, R., Karayilmazlar, S., 2019. Estimating modulus of elasticity (MOE) of particleboards using artificial neural networks to reduce quality measurements and costs. Drvna industrija, 70(3): 257-263.

Nzokou, P., Zyskowski, J., Boury, S., Kamdem, D.P., 2005. Natural decay resistance of LVL made of veneers from durable and nondurable wood species. Holz als Roh-und Werkstoff, 63(3): 173178.

Örs, Y., Keskin, H., 2008. Ağaç Malzeme Teknolojisi. Gazi Kitabevi, Ankara.

Pambou Nziengui, C.F., Ikogou, S., Moutou Pitti, R., 2018. Impact of cyclic compressive loading and moisture content on the mechanical behavior of Aucoumea Klaineana Pierre. Wood Material Science \& Engineering, 13(4): 190-196.

Pereira, P.J., Cortez, P., Mendes, R., 2021. Multi-objective grammatical evolution of decision trees for mobile marketing user conversion prediction. Expert Systems with Applications, 168: 114287. 
Roos, K., Edwardson, C., Adams, R., 1993. Manufacture of laminated veneer lumber from preservative treated veneers. IUFRO - symposium: protection of wood based composite products, 17-19 May, Orlando, Florida, pp: 69-78.

Sivrikaya, H., Can, A., de Troya, T., Conde, M., 2015. Comparative biological resistance of differently thermal modified wood species against decay fungi, Reticulitermes grassei and Hylotrupes bajulus. Maderas. Ciencia y tecnología, 17(3): 559570 .

Sözen, E., Bardak, T., Aydemir, D., Bardak, S., 2018. Yapay sinir ağları ve derin öğrenme algoritmaları kullanarak nanokompozitlerde deformasyonun tahmin edilmesi. Bartın Orman Fakültesi Dergisi, 20(2): 223-231.

Stark, N.M., Cai, Z., Carll, C., 2010. Wood-based composite materials panel products, glued-laminated timber, structural composite lumber, and wood-nonwood composite materials. In: Wood Handbook, Wood as an Engineering Material (Ed: Ross, R.J.), Centennial Edition, Madison, Wisconsin, pp:1-28

Tiryaki, S., Bardak, S., Bardak, T., 2015. Experimental investigation and prediction of bonding strength of Oriental beech (Fagus orientalis Lipsky) bonded with polyvinyl acetate adhesive. Journal of Adhesion Science and Technology, 29(23): 25212536.
TS 2471, 1976. Odunda fiziksel ve mekaniksel deneyler için rutubet miktarı tayini. TSE, Ankara.

TS 2472, 1976. Odunda Fiziksel ve mekaniksel deneyler için birim hacim ağırlı̆̆ı tayini. TSE, Ankara.

TS 2473, 1976. Odunun liflere dik doğrultuda basınçda denenmesi. TSE, Ankara.

TS 2595, 1977. Odunun liflere paralel doğrultuda basınç dayanımı tayini. TSE, Ankara.

Wadie, B.S., Badawi, A.M., Abdelwahed, M., Elemabay, S.M 2006. Application of artificial neural network in prediction of bladder outlet obstruction: A model based on objective, noninvasive parameters. Urology, 68(6): 1211-1214.

Wang, H., Li, W., Ren, D., Yu, Z., Yu, Y., 2014. A two-variable model for predicting the effects of moisture content and density on compressive strength parallel to the grain for moso bamboo. Journal of Wood Science, 60(5): 362-366. 